\title{
Zinc Oxide Nanoparticles Fabricated and Characterized from Mesophilic Bacteria (Escherichia coli) inhibits the growth of pathological microbes
}

\author{
Thirumalpur Neelakandan Baskaran, Sivaji Sathiyaraj, Gunasekaran Suriyakala, \\ Ponnurangam Dhivya and Ranganathan Babujanarthanam*
}

\author{
Nano and Energy Bioscience Laboratory, Department of Biotechnology, Thiruvalluvar \\ University, Serkkadu, Vellore-632115, Tamil Nadu, India \\ *Corresponding author
}

\section{A B S T R A C T}

\section{Keywords}

Nanotechnology, Bio-fabrication,

Zincoxide

Nanoparticles,

Antimicrobial,

Antioxidants

Article Info

Accepted:

14 April 2021

Available Online:

12 May 2021
The zinc oxide nanoparticles $(\mathrm{ZnO})$ have more compensations to the magnificent physical and chemical properties. In this study, we evaluate to green synthesis of $\mathrm{ZnO}$ nanoparticles from the source of mesophilic bacteria $(E$. coli) and characterized by several techniques such as UV spectroscopy, DLS, zeta potential, FTIR, XRD and SEM for conforming ZnONPs. Here we first we observed UV-vis spectra analysis that exhibits the spectra characteristic absorption peak of $\mathrm{Zn}$ nanocomposite material at $406 \mathrm{~nm}$. The particle size of $\mathrm{ZnO}$ was found to be $126.7 \mathrm{~nm}$ that was confirmed by DLS. FTIR results revealed that synthesized ZnONPs from mesophilic bacteria having several active functional groups were present. Moreover, crystal-based molecules found in the ZnONPs and it was confirmed by XRD. In our SEM results conformed the ZnONPs exhibits as crystal and irregular shape. Furthermore, the synthesized ZnONPs from mesophilic bacteria (E. coli) scavenges hydroxyl, superoxide, DPPH and ABTs radicals. In addition, ZnONPs from mesophilic bacteria shows potent antimicrobial activity by observing to inhibits the growth of Aspergillus niger, Aspergillus flavus, Fusarium and Rhizopus. This study concluded that efficient method to stably synthesis the ZnONPs by mesophilic bacteria (E. coli) that have potential antioxidants and antimicrobial activity.

\section{Introduction}

Nanotechnology signifies a novel and allowing platform to develop novel nanoparticles for a wide-ranging of biomedical inventions (Patra et al., 2018). Nanotechnology have been scientifically attracted much more interest through the last decades due to the compact, exclusive and exciting physical and chemical depending properties of the nanomaterials (Khan et al., 2019). The foremost advantage of nanomaterials can produce the particles ranges up to $100 \mathrm{~nm}$ in size with expecting controlling ability (Jeevanandam et al., 2018). There are several types of metal nanoparticles 
have used for numerous biomedical applications. Amongst, ZnONPs have been extensively used in cosmetic creams, sunscreen lotions to own effective UV absorbing properties (Jiang et al., 2018). Zinc is an imperative nutrient in a live organisms. Scientific studies have pointed that ZnONPs has exclusive biological applications, especially act as the antimicrobial agents (Ali et al., 2018). Moreover, several previous reports were stated that ZnONPs effectively inhibiting the growth of broad-spectrum of pathogens and potentially could substitute the conventional antibiotic (Yusof et al., 2019). Furthermore, zinc has been considered as an significant trace mineral that plays a crucial role in numerous physiological functions in the body. It has involved in the integration of NPs in feed would increase the absorption in the body, hence, result in improved health and productivity (Sahoo et al., 2014).

The biological synthesis methods of ZnONPs have been demonstrated by using biologically active products from plants and beneficiary microbes including bacteria, fungi and yeast. This has been promising method owing to its effectiveness, eco-friendly techniques, inexpensive, simple and exclusive productivity (Dhanker et al., 2021). Microorganisms such as yeast, fungi and bacteria crucially involved pivotal role in the biological synthesis of metal and metal oxide NPs. The use of microbes has been expanded to augmented attention in many studies led using various microorganisms' models ( $\mathrm{Li}$ et al., 2011).

However, the biological synthesis of ZnONPs using several microbes still remains unknown. The occurrence of numerous enzymes, protein and other biomolecules from microbes plays a vital role in the reduction process of NPs (Yusof et al., 2019). These multiple organic components secreted in the suspension or growth medium attributed to the formation of multiple sizes, shape with mono- and polydispersed NPs (Iravani 2014).

Escherichia coli (E. coli) is the family of gram-negative with rod-shape structured anaerobic mesophilic bacterium (Evans Jr and Evans, 1996). The bacterium considered as a thermo stable in nature because it producing enterotoxins (Butt et al., 2020). In this study, we evaluate to green synthesis of $\mathrm{ZnO}$ nanoparticles from the source of mesophilic bacteria $(E$. coli $)$ and characterized by several techniques. Furthermore, synthesized ZnONPs have been evaluated for free radical scavenging and antimicrobial activity.

\section{Materials and Methods}

\section{Chemicals}

Silver nitrate $\left(\mathrm{AgNO}_{3}\right)$ were procured from Sigma Merck Ltd, USA. Mesophilic bacteria's was collected from S. V. Veterinary Dairy University, Tirupathi, Chittoor district, Andhra Pradesh, India. All the solvents were used for this study is molecular grade.

\section{Isolation of Mesophilic bacteria from water samples}

Mesophilic bacteria samples (Water) (1ml) were taken suspended in $9 \mathrm{ml}$ sterile saline solution in a test tube and vortexed. Then $1 \mathrm{ml}$ of water was taken from the test tube and mixed with $9 \mathrm{ml}$ of sterile double distilled water in order to reduce the microbial load in the sample and marked as $10^{-2}$. This procedure was followed up to $10^{-7}$ dilution enumerated by pour plate technique using Nutrient agar (NA) medium for isolating bacteria. $1 \mathrm{ml}$ of sample was taken in a petriplate and Nutrient agar for bacteria was added thoroughly by rotating the plate in clockwise and anti-clock wise direction and allowed to solidify. Then the inoculated plates were incubated at $37^{\circ} \mathrm{C}$ triplicates were maintained for 2-3 days 
incubation Petri plates with 30-300 colonies were selected and the total viable counts/gm was made based on the following formula (Maheshwari et al., 2016).

Average number X $10 \mathrm{ml}$ of colony (av)

CFU = -----------volume of sample added $\mathrm{X}$ weight of scale sample

(av) = average for triplicate samples.

$10 \mathrm{ml}=$ volume of diluents

Many bacterial species were isolated fresh bacterial growth from the plated samples was then transferred on NA. Finally, every isolate was further purified by single- colony culture on NA. Nutrient broth (NB) medium was used for the harvesting of bacteria.

\section{Preparation of Mesophilic bacteria (E.coli) aqueous extract}

The pure culture of the E.coli was isolated from nutrient agar medium by using quaternary streaking method. The pure colony of the E.coli was taken and sub cultured on separate nutrient agar medium and the Fresh culture of the E.coli was stored in refrigerator at $4^{\circ} \mathrm{C}$ nutrient broth for further analysis. Extract was filtered by using Whatman No. 1 filter paper and collected in plastic bottle and stored at $4^{\circ} \mathrm{C}$ for further characterization and experimentation (Twum-Danso et al., 2013).

\section{Preparation of Mesophilic bacteria (E.coli) extract mediated Zinc (Zn) nanoparticles}

Zinc nitrate ( $>99 \%$ pure) was purchased from Sigma- Aldrich, India. Nutrient broth, nutrient agar plate, was supplied by Hi-Media, India. To prepare the ZnNPs, a $90 \mathrm{~mL}$ aqueous solution of $1.0 \times 10^{-3} \mathrm{M}$ zinc nitrate was mixed with a $10 \mathrm{~mL}$ of $5 \%$ aqueous solution of E.coli extract. The E.coli $\mathrm{Zn}$ solution was cream in color and the solution was stirred repeatedly for an hour, and it was observed that the color of the solution has been changed to yellow which visually confirms the formation of Nanoparticles. These E.coli zinc Nanoparticles were characterized by using the techniques such as UV-Vis spectrophotometry, Fourier transform infrared spectrophotometry (FT-IR), X-ray Diffractometry (XRD), Dynamic light scattering (Particle size), zeta potential, Scanning electron microscopy (SEM). The ZnNPs formed were stored for further characterization and bioactive assays (Rawat and Nair, 2010)

\section{Collection of microbes for Antimicrobial activity}

The microbes were collected from NCIM (National Collection of Industrial Microorganisms), Pune, Maharashtra. The bacterial names are Streptococcus(NCIM 2068), Pseudomonas (NCIM 5070), Bacillus pantothenticus (NCIM 2476), Staphylococcus aureus (NCIM 2127)and Salmonella typhimurium (NCIM 2501). The fungal names are Aspergillus flavus (NCIM 1316), Aspergillus niger (NCIM 1025), Fusarium oxysporium (NCIM 1043) and Rhizopus stolonifer (NCIM 1139).

Antimicrobial activity for Mesophilic bacteria (E.coli) mediated synthesized ZnNPs

The antibacterial activity of ZnNPs was evaluated against the following pathogenic strains Streptococcus, Salmonella typhimurium, Staphylococcus aureus, Pseudomonas fluorescence, Bacillus subtilis, these cultures were grown on appropriate medium at $37^{\circ} \mathrm{C}$ for overnight incubation and maintained at $4^{\circ} \mathrm{C}$ in a refrigerator. Disc diffusion method disc of $5 \mathrm{~mm}$ was made for 
nutrient agar medium and each disc was dipped at different concentration (150, 100 and $50 \mathrm{ppm}$ ) efficiency of prepared ZnNPs. The pure cultures of bacterial pathogens were sub-cultured on an appropriate medium. After incubation at $37^{\circ} \mathrm{C}$ for $24 \mathrm{~h}$ the zones of bacterial inhibition were measured. The assays were performed triplicate.

The antifungal activity of ZnNPs was evaluated against the following pathogenic strains fungal species viz., Aspergillus flavus, Aspergillus niger, Rhizopus oligosporus, and Fusarium oxysporium and these cultures were grown on appropriate medium at $25-28^{\circ} \mathrm{C}$ for overnight incubation and maintained at $4{ }^{\circ} \mathrm{C}$ in a refrigerator. Disc diffusion method disc of 5 $\mathrm{mm}$ was made on nutrient agar medium and each disc was dipped at different concentration (150, 100 and 50ppm) efficiency of prepared ZnNPs. The pure cultures of fungal pathogens were subcultured on an appropriate medium. After incubation at $37^{\circ} \mathrm{C}$ for $48 \mathrm{~h}$ the zones of fungal inhibition were measured. The assays were performed triplicate (Sharma et al., 2013).

\section{Antioxidant studies for Mesophilic bacteria} (E.coli) mediated synthesized zinc NPs

ZnONPs against DPPH- determined spectrophotometrically by Brand-Williams et al., (1995) DPPH. is a steady free radical and receives an electron or hydrogen radical to develop a stable diamagnetic molecule. $\mathrm{DPPH}$ - reacts with an antioxidant drugs that can donate hydrogen and gets reduced. The change in colour (from deep violet to light yellow) was measured. The intensity of the yellow colour depends on the amount and the nature of the radical scavenger present. The improved technique for the generation of $\mathrm{ABTS}^{+}$involves the direct production of blue/green colour chromophore through the reaction between ABTS + and potassium persulfate. ZnONPs and other antioxidants compete with ABTS + and diminish the colour formation. The $\mathrm{IC}_{50}$ value is the concentration of the compound required to inhibit $50 \%$ of radical production

\section{Results and Discussion}

Characterization of zinc nanoparticles from the extract of Mesophilic bacteria (E.coli)

\section{UV-visible Spectrum analysis}

The UV-vis absorption spectra (Figure 1) of $\mathrm{Zn}$ nanocomposite material was recorded at room temperature. The solution was used to record UV-vis spectra at wavelength range between 200 and $800 \mathrm{~nm}$. The spectra reveal a characteristic absorption peak of $\mathrm{Zn}$ nanocomposite material at $406 \mathrm{~nm}$ (Figure1). The absorbance increases in the higher wavelength side indicating the role of nano $\mathrm{Zn}$. More number of $\mathrm{Zn}$ and these metallic particles rest on the surface of $\mathrm{Zn}$ nanocomposite making the surface area more and showing plasmonic resonance peak in the UV-vis spectra. This is an important method in which $\mathrm{Zn}$ composite nano rod has been showed and elevated by UV absorption. This high absorbance of the $\mathrm{Zn}$ composite nanorods has an important implication for various industrial applications (Supraja et al., 2016).

\section{Fourier transformance infrared spectroscopic analysis}

The functional groups such as alcohols, phenols, alkenes, alkanes, carbonyls, aromatics, nitro compounds, alkyl halides and aliphatic amines were identified from FT-IR spectrum recorded from the aqueous extract of Sargassum muticum. The peak present at 3408, 3400, 1624, 1361, 1151, 1122 and 1087 indicates $\mathrm{N}-\mathrm{H}$ stretching vibration of primary and secondary amines (Figure 2). The peak present at 655 indicates $\mathrm{C}-\mathrm{H}$ stretching 
vibration of alkanes. The strong band of $\mathrm{C}=\mathrm{O}$ - stretch (carboxylic acids) was recorded at $613 \mathrm{~cm}^{-1}$. The peak present at 599 indicates $\mathrm{C}-\mathrm{Br}$ stretching vibration of alkyl halides (Supraja et al., 2016)

\section{X-ray Diffraction analysis}

The average crystallite size can be determined through Full-width at Half Maximum (FWHM) of X-Ray diffraction peak by using Debye-Scherer's equation as

$\mathrm{D}=0.9 \lambda / \beta \operatorname{Cos} \theta$

Where, D - Grain size (nm), $\lambda$ - Wavelength of the XRD used, $\beta$ - FWHM, $\theta$ - Bragg's angle. $\mathrm{X}$-ray diffractogram, was analyzed to obtain information about various crystalline aspects of $\mathrm{Zn}$ nanocomposite material. The X-Ray diffraction patterns of $\mathrm{Zn}$ nanocomposite material are wurtzite hexagonal phase and were shown in (Figure 3) which indicates the well-indexed XRD peaks corresponding to the planes (100), (002), (111) and (101) indicates the presence of Zinc ( $\mathrm{Zn})$ and no other impurities observed (Supraja et al., 2018).

\section{Dynamic light scattering analysis}

Particle size and zeta potential values were measured using Nanopartica SZ-100. The particle size distribution spectra for the silver nanoparticles were recorded as diameter $(\mathrm{nm})$ verses frequency $(\% / \mathrm{nm})$ spectra with diameter (nm) on $\mathrm{x}$-axis and frequency $(\% / \mathrm{nm})$ on $\mathrm{y}$-axis. The zeta potential spectra for the silver nanoparticles were recorded zeta potential verses intensity spectra with zeta potential $(\mathrm{mV})$ on $\mathrm{x}$-axis and intensity (a.u) on $y$-axis. Dynamic light scattering technique has been used to measure hydrodynamic diameter of the hydrosol (particle suspension). Mesophilic bacteria (E.coli) zinc NPs was found to be $126.7 \mathrm{~nm}$ the recorded value of zeta potential of the zinc nanoparticles was $0.2 \mathrm{mV}$, which resulted in the agglomerated state of the formed ZnNPs (Figure 4).

\section{Scanning electron microscopic analysis}

The SEM uses a focused beam of higher energy electrons to generate a variety of signals at the surface of solid specimens. The signals that derive from electron sample interactions reveal information about the sample including external morphology. When samples were view under SEM, the truncated nano-rod morphology with irregular size was observed, which was randomly orientated. The diameter and length of the Zinc nano-rod were found approximately 10 to $100 \mathrm{~nm}$ length with one-dimension was segregated (Moumen et $a l ., 2020)$. The surface morphology, size and shape of zinc nanoparticles were characterized from the SEM micrograph, it is evident that zinc NPs were spherical and irregular in shape and were poly-dispersed. The measured average size was $20 \mu \mathrm{m}$, Occasional agglomeration of the zinc NPs has been observed (Figure 5). These results indicate that the products consisted of pure phases.

Furthermore, the diffraction peaks were more intensive and narrower, implying a good crystalline nature of $\mathrm{Ag}$ and $\mathrm{Zn}$ nanocomposite products. The zinc nanocomposite material changes spherical $\mathrm{Zn}$ to rod shape The entire particle sizes results obtained were almost same in XRD, DLS, SEM when comparing with one other. Finally, it confirmed by the comprehensible techniques such as SEM. 
Table.1 Antibacterial activity of Mesophilic bacteria (E.coli) extract mediated synthesized ZnNPs

\begin{tabular}{|c|c|c|c|c|}
\hline \multirow[t]{2}{*}{ S. no } & \multirow[t]{2}{*}{ Bacteria } & \multicolumn{3}{|c|}{$\begin{array}{c}\text { Mesophilic bacteria (E.coli) extract mediated } \\
\text { synthesis of zinc nanoparticles Zone of inhibition } \\
(\mathrm{mm})\end{array}$} \\
\hline & & $150 \pm 1.4 p p m$ & $100 \pm 1.1 p p m$ & $50 \pm 0.9 \mathrm{ppm}$ \\
\hline 1. & Staphylococcus aureus & $2.3 \pm 0.05^{\mathrm{a}}$ & $1.2 \pm 0.02^{\mathrm{c}}$ & $0.9 \pm 0.02^{\mathrm{a}}$ \\
\hline 2. & Streptococcus & $2.2 \pm 0.06^{\mathrm{a}}$ & $2.0 \pm 0.02^{\mathrm{ab}}$ & $1.0 \pm 0.04^{\mathrm{a}}$ \\
\hline 3. & Pseudomonas aeruginosa & $2.0 \pm 0.07^{\text {cdef }}$ & $1.0 \pm 0.02^{\mathrm{de}}$ & $0.3 \pm 0.16^{\mathrm{de}}$ \\
\hline 4. & Bacillus subtilis & $2.0 \pm 0.17^{\text {cdef }}$ & $1.3 \pm 0.02^{b}$ & $1.0 \pm 0.06^{\mathrm{a}}$ \\
\hline 5. & Salmonella & $2.0 \pm 0.14^{\mathrm{abc}}$ & $1.1 \pm 0.02^{\mathrm{d}}$ & $0.4 \pm 0.05^{\mathrm{ab}}$ \\
\hline & C.R.D (P $\leq \mathbf{0 . 0 5})$ & 0.220 & 0.215 & 0.150 \\
\hline
\end{tabular}

Table.2 Antifungal activity of Mesophilic bacteria (E.coli) extract mediated synthesized ZnNPs

\begin{tabular}{|c|c|c|c|c|}
\hline \multirow[t]{2}{*}{ S. no } & \multirow[t]{2}{*}{ Fungi } & \multicolumn{3}{|c|}{$\begin{array}{l}\text { Mesophilic bacteria (E.coli) extract mediated } \\
\text { synthesis of zinc nanoparticles Zone of inhibition } \\
(\mathbf{m m})\end{array}$} \\
\hline & & $150 \pm 1.4 p p m$ & $100 \pm 1.1 p p m$ & $50 \pm 0.9 p p m$ \\
\hline 1. & Aspergillus niger & $4.6 \pm 0.17^{\mathrm{a}}$ & $2.0 \pm 0.02^{\mathrm{de}}$ & $1.2 \pm 0.04^{\mathrm{a}}$ \\
\hline 2. & Aspergillus flavus & $3.1 \pm 0.06^{\mathrm{abcd}}$ & $1.4 \pm 0.01^{\mathrm{f}}$ & $1.2 \pm 0.08^{\mathrm{abc}}$ \\
\hline 3. & Fusarium oxysporium & $3.0 \pm 0.03^{\mathrm{ab}}$ & $2.0 \pm 0.08^{\mathrm{e}}$ & $1.6 \pm 0.04^{\mathrm{a}}$ \\
\hline 4. & Rhizopus oryzae & $2.2 \pm 0.05^{\mathrm{a}}$ & $1.5 \pm 0.04^{\mathrm{a}}$ & $1.0 \pm 0.03^{\mathrm{d}}$ \\
\hline & C.R.D (P $\leq 0.05)$ & 0.510 & 0.352 & 0.230 \\
\hline
\end{tabular}

Fig.1 UV absorbance spectrum of ZnONPs synthesized from mesophilic bacteria

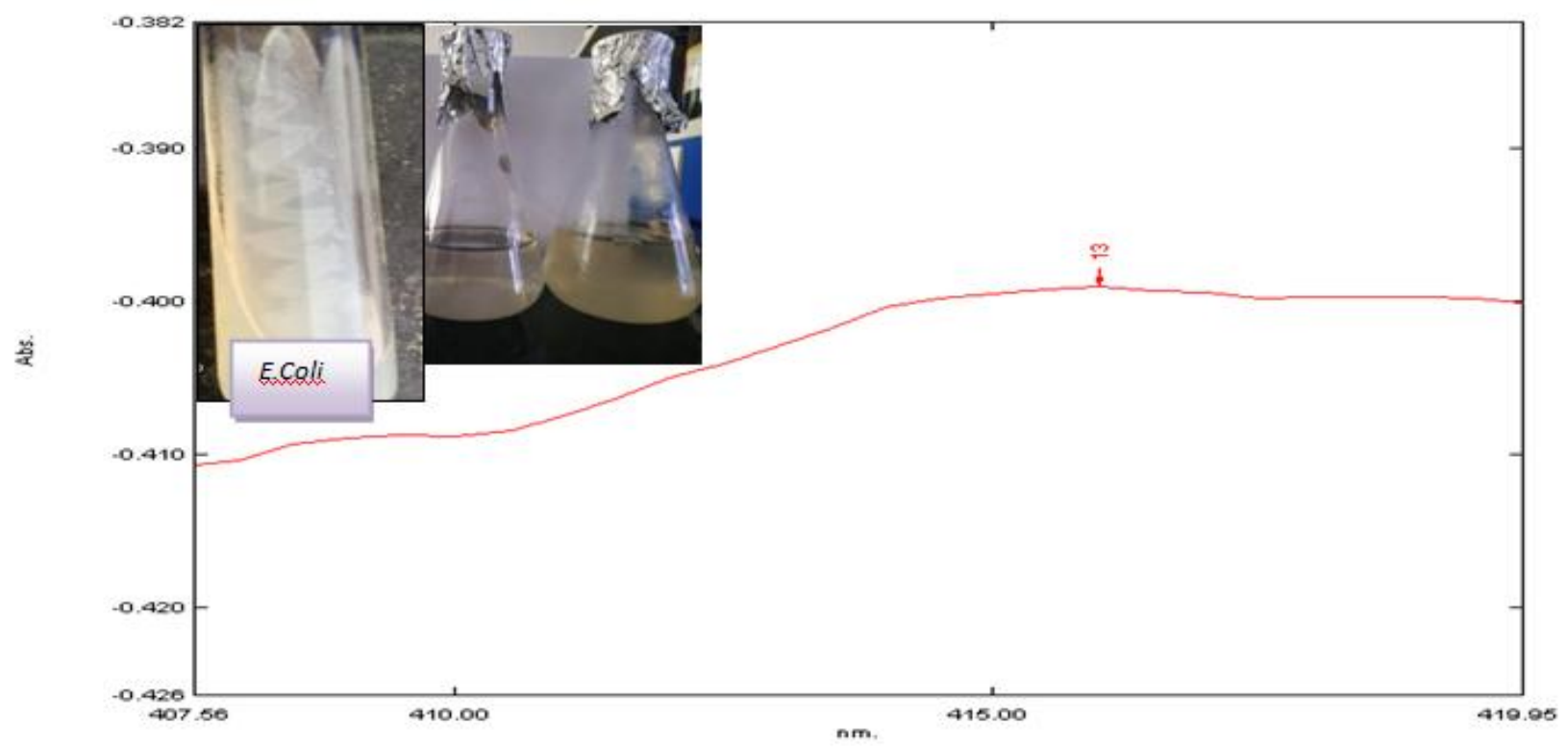


Fig.2 DLS analysis of Mesophilic bacteria (E.coli) mediated synthesized ZnNPs
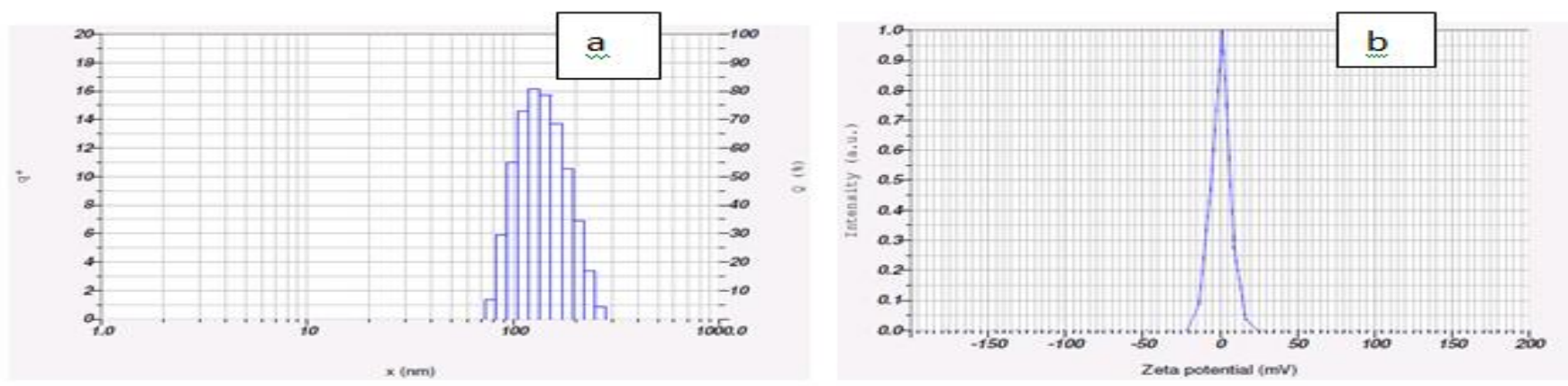

Calculation Results

\begin{tabular}{|c|c|c|c|c|}
\hline Peak No. & S.P.Area Ratio & Mean & S. D. & Mode \\
\hline 1 & 1.00 & $141.6 \mathrm{~nm}$ & $38.8 \mathrm{~nm}$ & $126.7 \mathrm{~nm}$ \\
\hline 2 & - & $-\mathrm{nm}$ & $-\mathrm{nm}$ & $-\mathrm{nm}$ \\
\hline 3 & - & $-\mathrm{nm}$ & $-\mathrm{nm}$ & $-\mathrm{nm}$ \\
\hline Total & 1.00 & $141.6 \mathrm{~nm}$ & $38.8 \mathrm{~nm}$ & $126.7 \mathrm{~nm}$ \\
\hline
\end{tabular}

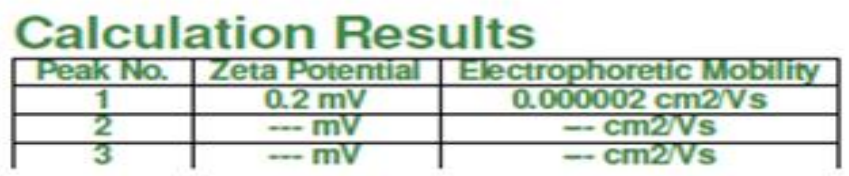

Fig.3 FT-IR spectrum of Mesophilic bacteria (E.coli) mediated synthesized ZnNPs

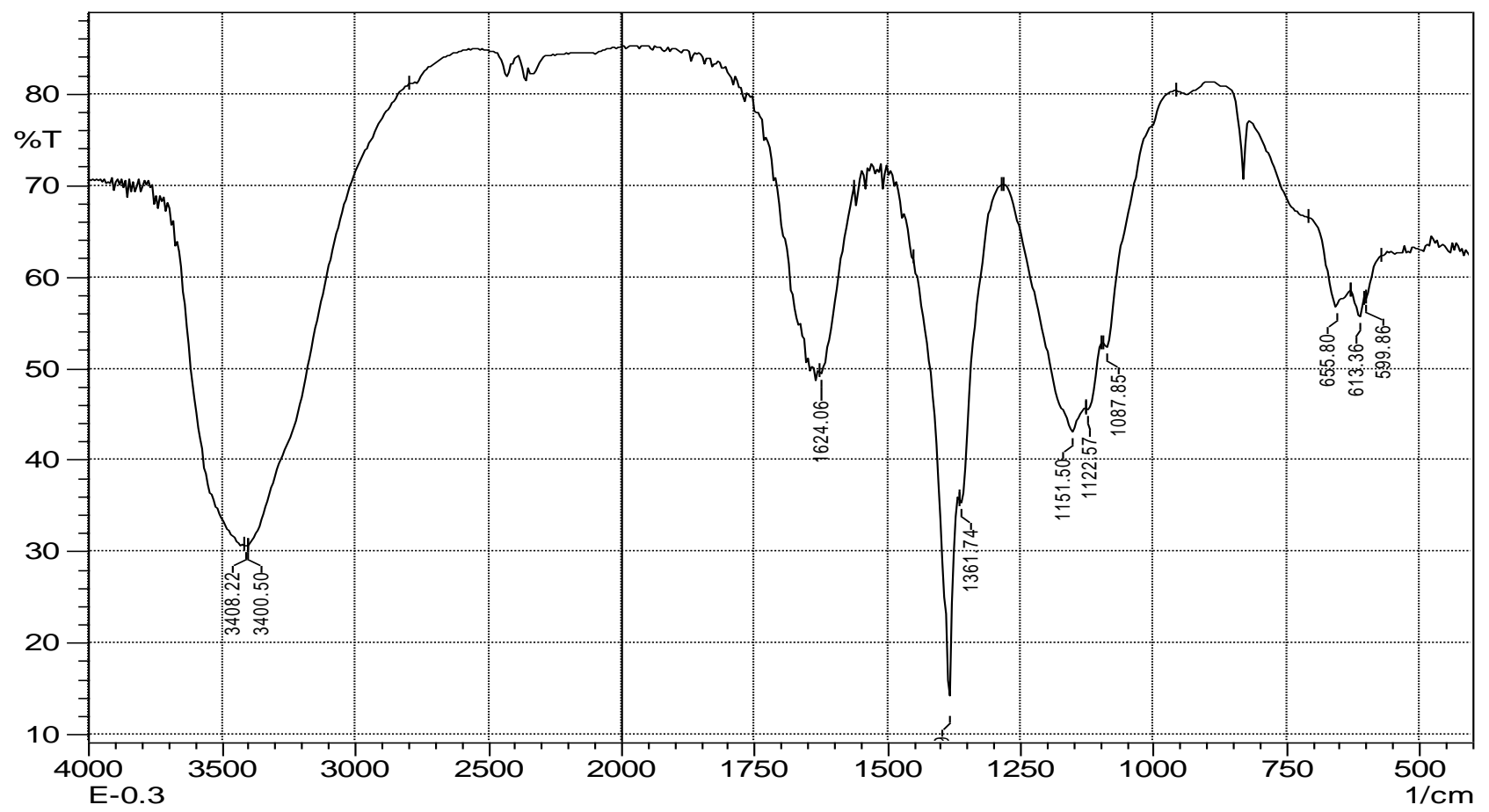


Fig.4 XRD spectrum of Mesophilic bacteria (E.coli) mediated synthesized ZnNPs

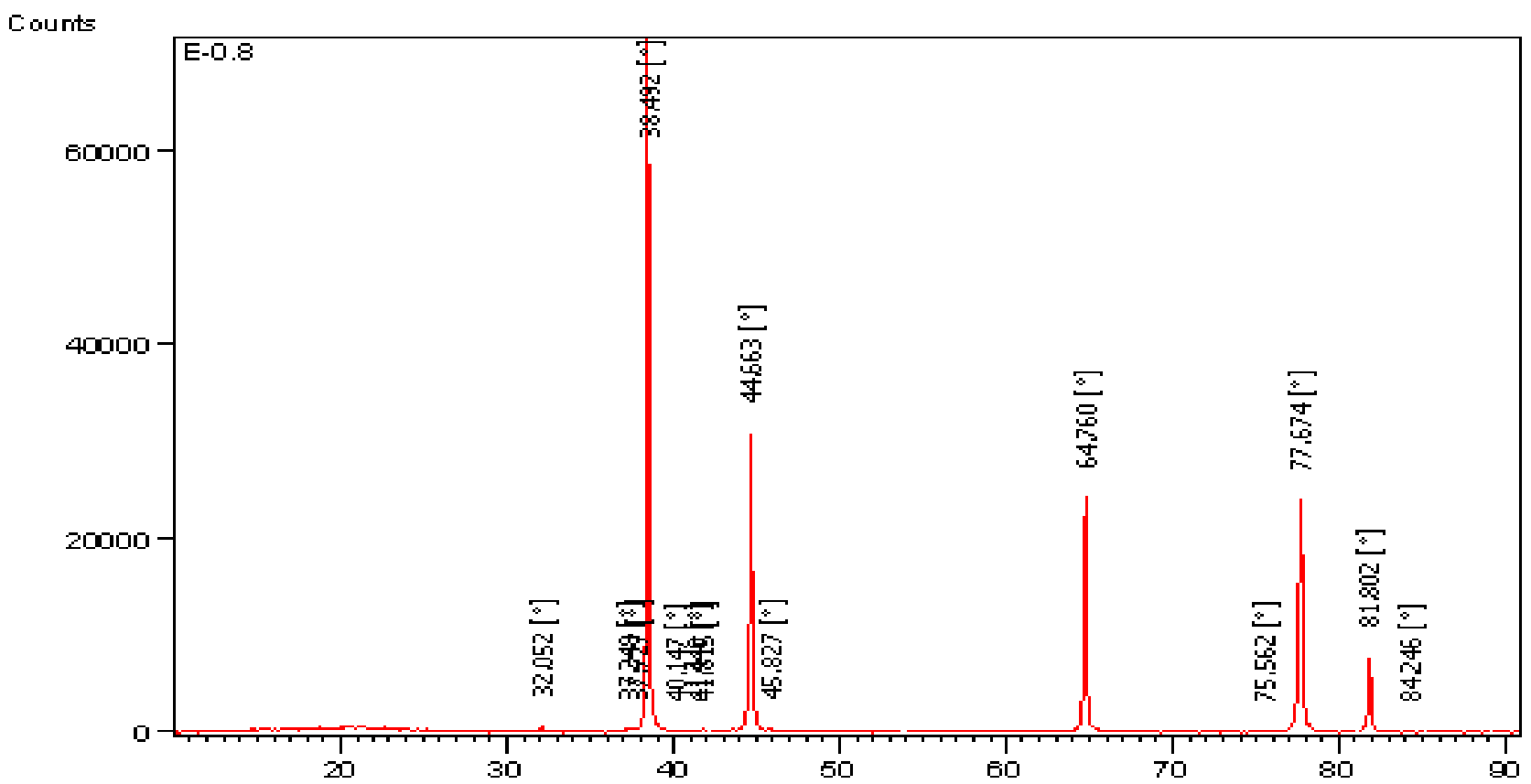

Fig.5 SEM images of Mesophilic bacteria (E.coli) mediated synthesized ZnNPs

\section{a}

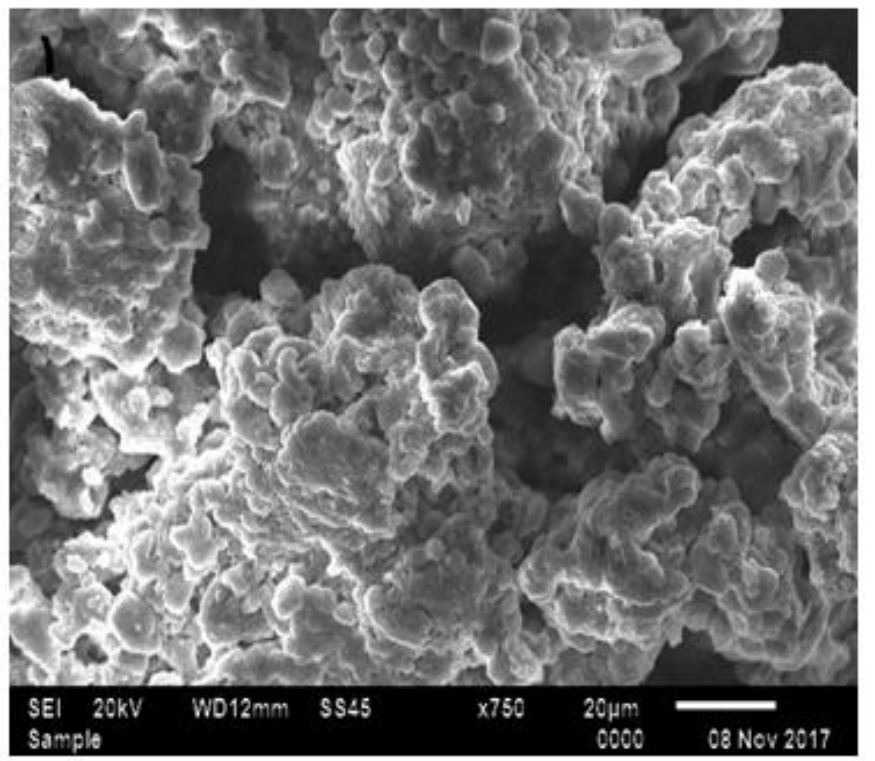

b

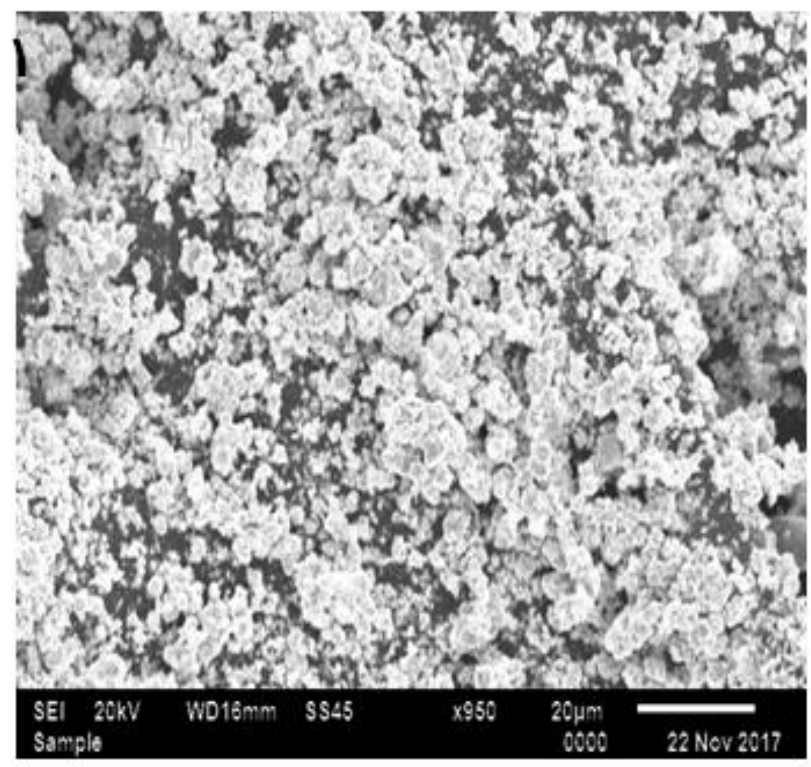


Fig.6 In Vitro antioxidants activity of mesophilic bacteria mediated synthesized ZnONPs. A) ABTS radical scavenging activity. B) DPPH radical scavenging activity. Standard vitamin-c have been used for standard control.

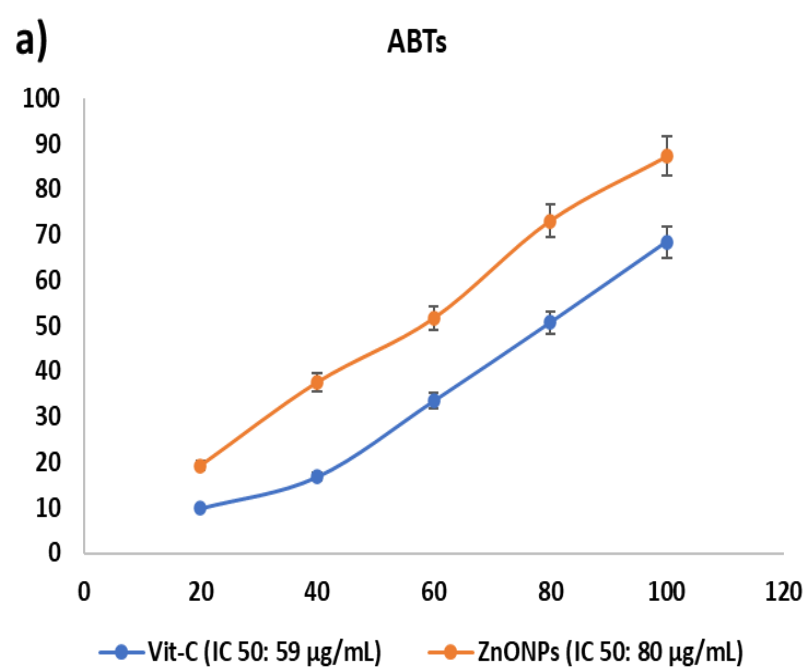

Antimicrobial potential assay of formed ZnNPs tested bacterial and fungal species Mesophilic bacteria (E.coli)

The antimicrobial activity of the synthesized ZnNPs was carried out using the method proposed by Kirby-Bauer (Punjabi et al., 2018). ZnNPs obtained from Mesophilic bacteria $(E . C o l i)$ have very strong inhibitory action against Gram-positive-negative bacteria and fungi. Three concentrations of ZnNPs were prepared and were applied against an array of bacterial species viz, S. aureus (Gram positive), Streptococcus, Bacillus and $P$. aeruginosa (Gram negative). The higher concentration (170 ppm) of ZnNPs showed significant antimicrobial effect compared with other concentrations (100 and $50 \mathrm{ppm}$ ). But when compared to Streptococcus and $S$. aureus (Gram positive) P. aeruginosa (Gram negative) and Bacillus (Gram positive) shown effective zone of inhibition in all concentrations. While coming to fungal species when compared to Aspergillus niger, Aspergillus flavus, Fusarium and Rhizopus

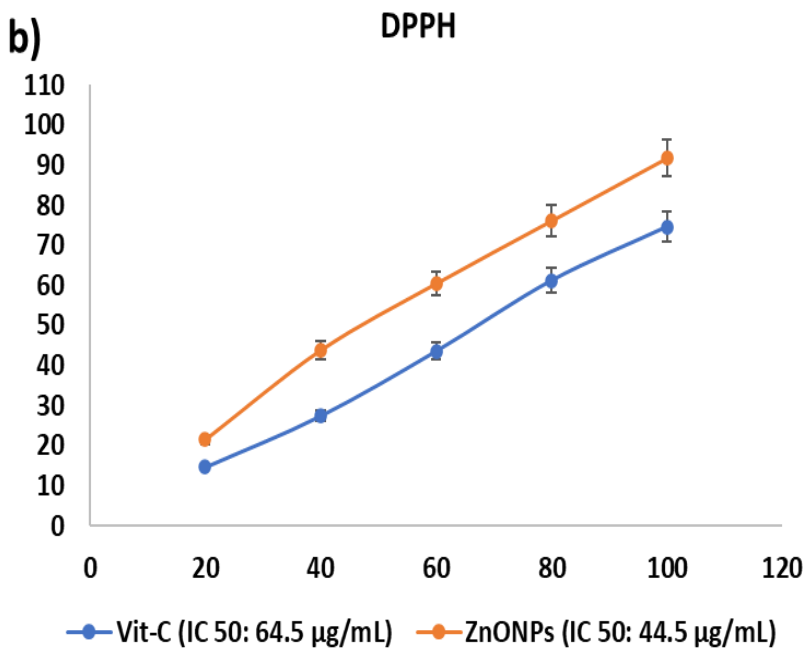

shown very good inhibition activity at higher concentrations (150 and $100 \mathrm{ppm}$ ).

The inhibitory action of the microbes may be attributed to the loss of replication ability of DNA upon treatment with the zinc ion, besides the fact that expression of ribosomal sub-unit proteins as well as some other cellular proteins and enzymes essential to ATP production becomes inactivated because it is due to the release of Reactive oxygen species (ROS) (Elumalai et al., 2010; Prasad and Elumalai, 2011). When ppm concentration decreases the diameter of zone of inhibition was also decreased. The results indicated that antimicrobial effect was done by dose dependent. The mechanism of inhibition of ZnNPs on microorganisms is not well known. ZnNPs binds with cytoplasmic membrane and killed the bacterial and fungal cells. This is because the electrostatic interaction between positively charged ZnNPs and negatively charged cell membrane of microorganisms. The observed results of the antimicrobial assay of ZnNPs are given in (Table. $1 \& 2$ ). 
Antioxidant activity of Mesophilic bacteria (E.coli) extract mediated synthesized Zinc Nanoparticles

The antioxidant activity of the aqueous extracts of Mesophilic bacteria (E.coli) extract mediated synthesized ZnNPs was evaluated using ABTs and DPPH scavenging assays. A significant difference was observed among the respective values obtained. ABTS assay is an excellent tool for determining the antioxidant activity of hydrogen ion donating antioxidants and of chain-breaking antioxidants (Leong and Shui, 2002).The percentage of $\mathrm{ABTS}^{+}$radical scavenging activity of ZnONPs were improved when the addition of increased concentration of ZnONPs. The $\mathrm{IC}_{50}$ concentration of ZnONPs shows $80 \mu \mathrm{g} / \mathrm{mL}$ whereas vitamin-c was found to be at 59 $\mu \mathrm{g} / \mathrm{mL}$. DPPH radical scavenging assay was investigated for the evaluation of antioxidant potential of ZnONPs from mesophilic bacteria. The purple solution containing DPPH turns yellow on addition of nanoparticles, which designates the scavenging of free radicals due to presence of antioxidant activity. Thus, it can be concluded that maximum concentration of extract revealed maximum percent inhibition.

In this present study, observed the $\mathrm{IC}_{50}$ value of $\mathrm{ZnONPs}$ exhibits $44.5 \mu \mathrm{g} / \mathrm{mL}$ whereas vit-c shows the $64.5 \mu \mathrm{g} / \mathrm{mL}$ (Fig.6). The biologically active compounds such as phenolic and flavonoid compounds are main agents for the antioxidant activity they can donate hydrogen to free radicals and break the lipid oxidation chain reaction (Ningappa and Srinivas, 2008; Zahin et al., 2013; Ningappa et al., 2016). The green synthesis of $\mathrm{ZnO}$ nanoparticles from the source of mesophilic bacteria $(E$. coli $)$ and characterized by several techniques such as UV spectroscopy, DLS, zeta potential, FTIR, XRD and SEM for conforming ZnONPs. These characterized data confirmed that the synthesized particles are ZnONPs and it exhibits very compact, polydispersed, irregular in shape, crystalbased structure and $126.7 \mathrm{~nm}$ in size. Furthermore, the synthesized ZnONPs from mesophilic bacteria (E. coli) scavenges hydroxyl, superoxide, DPPH and ABTs radicals. In addition, ZnONPs from mesophilic bacteria shows potent antimicrobial activity by observing to inhibits the growth of Aspergillus niger, Aspergillus flavus, Fusarium and Rhizopus. This study concluded that efficient method to stably synthesis the ZnONPs by mesophilic bacteria (E. coli) that have potential antioxidants and antimicrobial activity.

\section{Acknowledgment}

The authors acknowledge Department of Biotechnology, Thiruvalluvar University, Serkkadu, Vellore, Tamil Nadu-632115, India, for providing laboratory facilities to carry out the research work.

\section{References}

Abdel-Aziz, M. S., Shaheen, M. S., El-Nekeety, A. A., and Abdel-Wahhab, M. A. 2014. Antioxidant and antibacterial activity of silver nanoparticles biosynthesized using Chenopodium murale leaf extract. Journal of Saudi Chemical Society. 18(4):356-63.

Ali, A., Phull, A. R., and Zia, M. 2018. Elemental zinc to zinc nanoparticles: Is $\mathrm{ZnO}$ NPs crucial for life? Synthesis, toxicological, and environmental concerns. Nanotechnology Reviews.7(5):413-41.

Brand-Williams, W., Cuvelier, M. E., and Berset, C. L. 1995. Use of a free radical method to evaluate antioxidant activity. LWT-Food science and Technology. 28(1):25-30.

Butt, S., Saleh, M., and Gagnon, J. 2020. Impact of the Escherichia coli Heat-Stable 
Enterotoxin b (STb) on Gut Health and Function. Toxins. 12(12):760.

Dhanker, R., Hussain, T., Tyagi, P., Singh, K. J., and Kamble, S. S. 2021. The emerging trend of bio-engineering approaches for microbial nanomaterial synthesis and its applications. Frontiers in Microbiology. 12.

Elumalai, E. K., Prasad, T. N., Venkata, K., Nagajyothi, P. C., and David, E. 2010. Green synthesis of silver nanoparticle using Euphorbia hirta L and their antifungal activities. Archives of Applied Science Research. 2(6):76-81.

Evans Jr, D. J., and Evans, D. G. 1996. Escherichia coli in diarrheal disease. Medical Microbiology. 4th edition.

Iravani, S. 2014. Bacteria in nanoparticle synthesis: current status and future prospects. International scholarly research notices. 2014;2014.

Jeevanandam, J., Barhoum, A., Chan, Y. S., Dufresne, A., and Danquah, M. K. 2018. Review on nanoparticles and nanostructured materials: history, sources, toxicity and regulations. Beilstein journal of nanotechnology.9(1):1050-74.

Jiang, J., Pi, J., and Cai, J. 2018. The advancing of zinc oxide nanoparticles for biomedical applications. Bioinorganic chemistry and applications. 2018.

Khan, I., Saeed, K., and Khan, I. 2019. Nanoparticles: Properties, applications and toxicities. Arabian journal of chemistry. 12(7):908-31.

Li, X., Xu, H., Chen, Z. S., and Chen, G. 2011. Biosynthesis of nanoparticles by microorganisms and their applications. Journal of Nanomaterials. 2011.

Maheshwari, M., Ahmad, I., and Althubiani, A. S. 2016. Multidrug resistance and transferability of bla CTX-M among extended-spectrum $\quad \beta$-lactamaseproducing enteric bacteria in biofilm. Journal of Global Antimicrobial Resistance. 6: 142-149.

Maheshwari, M., Ahmad, I., andAlthubiani, A. S. 2016. Multidrug resistance and transferability of blaCTX-M among extended-spectrum $\quad \beta$-lactamaseproducing enteric bacteria in biofilm. Journal of global antimicrobial resistance. 6:142-9.

Moumen, A., Kaur, N., Poli, N., Zappa, D., and Comini, E. 2020. One dimensional $\mathrm{ZnO}$ nanostructures: Growth and chemical sensing performances. Nanomaterials. 10(10): 1940.

Ningappa, M. B., and Srinivas, L. 2008. Purification and characterization of $\sim 35$ $\mathrm{kDa}$ antioxidant protein from curry leaves (Murraya koenigii L.). Toxicology in vitro. 22(3):699-709.

Ningappa, M. B., Ramadas, D., Nanjegowda, D., Balasubramanian, K., Chahal, K., Patil, S., and Srinivas, L. 2016. Cytoprotective properties of antioxidant protein from curry leaves (Murraya koenigii L.) against oxidative stress induced damage in human erythrocytes. Medicinal chemistry. 6(2):2161-0444.

Patra, J. K., Das, G., Fraceto, L. F., Campos, E. V., del Pilar Rodriguez-Torres, M., Acosta-Torres, L. S., Diaz-Torres, L. A., Grillo, R., Swamy, M. K., Sharma, S., and Habtemariam, S. 2018. Nano based drug delivery systems: recent developments and future prospects. Journal of nanobiotechnology.16(1): 133.

Prasad, T. N., and Elumalai, E. K. 2011. Biofabrication of $\mathrm{Ag}$ nanoparticles using Moringa oleifera leaf extract and their antimicrobial activity. Asian Pacific Journal of Tropical Biomedicine. 1(6):439-42.

Punjabi, K., Mehta, S., Chavan, R., Chitalia, V., Deogharkar, D., and Deshpande, S. 2018. Efficiency of biosynthesized silver and zinc nanoparticles against multidrug resistant pathogens. Frontiers in microbiology. 9:2207.

Rawat, D., and Nair, D. 2010. Extendedspectrum $\beta$-lactamases in Gram Negative Bacteria. Journal of global infectious diseases. 2(3):263. 
Sahoo, A., Swain, R. K., and Mishra, S. K. 2014. Effect of inorganic, organic and nano zinc supplemented diets on bioavailability and immunity status of broilers. Int. J. Adv. Res. 2(11):828-37

Sharma, N., Kumar, J., Thakur, S., Sharma, S., and Shrivastava, V. 2013. Antibacterial study of silver doped zinc oxide nanoparticles against Staphylococcus aureus and Bacillus subtilis. Drug Invention Today. 5(1):50-4.

Supraja, N., Dhivya, J., Prasad, T. N., and David, E. 2018. Synthesis, characterization and dose dependent antimicrobial and anticancerous efficacy of phycogenic (Sargassum muticum) silver nanoparticles against Breast Cancer Cells (MCF 7) cell line. Advances in nano research. 6(2):183.

Supraja, N., Prasad, T. N., Gandhi, A. D., Anbumani, D., Kavitha, P., and Babujanarthanam, R. 2018. Synthesis, characterization and evaluation of antimicrobial efficacy and brine shrimp lethality assay of Alstonias cholaris stem bark extract mediated ZnONPs. Biochemistry and biophysics reports. 14:69-77.

Supraja, N., Prasad, T. N., Krishna, T. G., and David, E. 2016. Synthesis, characterization, and evaluation of the antimicrobial efficacy of Boswellia ovalifoliolata stem bark-extractmediated zinc oxide nanoparticles. Applied Nanoscience. 6(4):581-90.

Supraja, N., Prasad, T. N., Soundariya, M., and Babujanarthanam, R. 2016. Synthesis, characterization and dose dependent antimicrobial and anti-cancerous activity of phycogenic silver nanoparticles against human hepatic carcinoma (HepG2) cell line. AIMS Bioeng. 3(4):425-40.

Twum-Danso, K., Newman, M. J., ObengNkrumah, N., and Krogfelt, K. A.2013. High levels of extended-spectrum betalactamases in a major teaching hospital in Ghana: the need for regular monitoring and evaluation of antibiotic resistance. American Journal of Tropical Medicine and Hygiene. 89: 960-964.

Yusof, H. M., Mohamad, R., and Zaidan, U. H. 2019. Microbial synthesis of zinc oxide nanoparticles and their potential application as an antimicrobial agent and a feed supplement in animal industry: a review. Journal of animal science and biotechnology.10(1):1-22.

Zahin, M., Aqil, F., Husain, F. M., and Ahmad, I. 2013. Antioxidant capacity and antimutagenic potential of Murraya koenigii. BioMed research international. 2013.

\section{How to cite this article:}

Thirumalpur Neelakandan Baskaran, Sivaji Sathiyaraj, Gunasekaran Suriyakala, Ponnurangam Dhivya and Ranganathan Babujanarthanam. 2021. Zinc Oxide Nanoparticles Fabricated and Characterized from Mesophilic Bacteria (Escherichia coli) inhibits the growth of pathological microbes. Int.J.Curr.Microbiol.App.Sci. 10(05): 436-447. doi: https://doi.org/10.20546/ijcmas.2021.1005.051 